Allan Gustavo Bregola'

(ㄱ) https://orcid.org/0000-0003-0265-4940

Ana Carolina Ottaviani²

(- https://orid.org/0000-0003-4037-4587

Bruna Moretti Luchesi ${ }^{3}$

(- https://orcid.org/0000-0002-0508-0818

Sofia Cristina lost Pavarinit

(ㅇ) https://orcid.org/0000-0001-9359-8600

\section{Demographics and stress as risk factors associated with mortality in older adults who provide daily support and who receive daily support}

\author{
Dados demográficos e estresse como fatores de risco associados à \\ mortalidade de idosos cuidadores e idosos receptores de cuidado
}

D0I: $10.1590 / 0047-2085000000329$

\begin{abstract}
Objective: Despite the greater vulnerability of care providers, the literature shows that their mortality rate is considerably lower compared to care recipients. The aim of the present study was to analyze the mortality rates of community-dwelling older adults who provided support in activities of daily living $(A D L)$ (group $P C$ ) and older adults who received in activities of daily living (group $R C$ ) in a four-year period considering the effects of age, sex and schooling in both groups and stress in in group PC. Methods: 261 older adults PC and 279 older adults RC participated in the study. In 2014, we collected data on demographic characteristics and functioning. In 2018, the participants were contacted a second time and information on deaths was obtained. The mortality rate was calculated for each group. Results: Death cases in four years were considerably higher among the group who were receiving support. The mortality rate was $12.6 \%$ in the PC group and $31.2 \%$ in the RC group. In deceased PC, 69\% presented with high-perceived stress in baseline. About half of the PC were independent, whereas the RC group exhibited some functional dependence in 2014. There was no association between risk factors in the group PC, however the female sex was marginally associated with the risk of mortality among the RC (HR: 1.7 [95\% Cl: 0.9-3.0]). Conclusion: Some demographic characteristics have been considered risk factors for the mortality of the old age population, however these were not confirmed in this study among the older adults who provided and received care.
\end{abstract}

KEYWORDS

Psychological stress, older adults, caregivers, mortality, longitudinal studies.

\section{RESUMO}

Objetivo: Apesar da maior vulnerabilidade dos idosos cuidadores, a literatura mostra que sua taxa de mortalidade é consideravelmente menor em comparação aos pares que não cuidam ou que recebem cuidados. O objetivo do presente estudo foi analisar as taxas de mortalidade de idosos que proveem suporte nas atividades da vida diária (ADLs) (denominado grupo PC) e idosos que recebem suporte nas ADLs (denominado grupo RC) na comunidade, em um período de quatro anos, considerando os efeitos da idade, sexo e escolaridade nos dois grupos e estresse no grupo PC. Métodos: Duzentos e sessenta e um idosos PC e 279 idosos RC participaram do estudo. Em 2014, foram coletados dados sobre características demográficas e funcionalidade. Em 2018, os participantes foram contatados pela segunda vez e foram obtidas informações sobre óbitos. A taxa de mortalidade foi calculada para cada grupo. Resultados: Os casos de óbito em quatro anos foram consideravelmente maiores entre o grupo que recebia suporte. A taxa de mortalidade foi de $12,6 \%$ no grupo PC e de $31,2 \%$ no grupo RC. Entre o grupo que ofertava suporte funcional (PC) que faleceu, $69 \%$ apresentaram alto estresse percebido em 2014. Cerca de metade do grupo PC era independente, enquanto o grupo RC exibiu alguma dependência funcional em 2014. Não houve relação entre fatores de risco no grupo PC, todavia o sexo feminino foi marginalmente associado ao risco de mortalidade entre RC (HR: 1,7 [IC 95\%: 0,9-3,0]). Conclusão: Algumas características demográficas têm sido consideradas fatores de risco para a mortalidade da população idosa, no entanto elas não foram confirmadas nesse estudo entre os idosos que proviam e recebiam cuidados.

\section{PALAVRAS-CHAVE}

Estresse psicológico, adultos mais velhos, cuidadores, mortalidade, estudos longitudinais.

Received in: July/20/2020. Approved in: Mar/12/2021

1 Federal University of São Carlos, Nursing Post-Graduation Program, São Carlos, SP, Brazil. School of Health Sciences, University of East Anglia, Norwich Research Park, United Kingdom.

2 Federal University of São Carlos, Nursing Post-Graduation Program, São Carlos, SP, Brazil.

3 Federal University of Mato Grosso do Sul, Faculty of Medicine, Três Lagoas, MS, Brazil.

4 Federal University of São Carlos, Department of Gerontology, São Carlos, SP, Brazil.

Address for correspondence: Allan Gustavo Bregola. E-mail: allanbrig@gmail.com 


\section{INTRODUCTION}

The chronic stress, depression and anxiety that stem from the daily task of providing care for a dependent loved one can compromise the mental health and psychological wellbeing of the caregiver'. Caregivers of older adults tend to have more depressive symptoms and care-related stress, less self-efficacy, lower subjective wellbeing and different levels of physical health compared to non-caregivers ${ }^{2}$. Considering specific characteristics, such as sex, a meta-analysis found that female caregivers have higher levels of depression and burden as well as lower levels of subjective wellbeing and self-rated health. Women report more problems related to the behavior of the care recipient, provide care for more hours per week, assist in more activities and provide more intimate care to older dependent individuals, but no differences between sexes are found in terms of the use of formal or informal support ${ }^{3}$.

According to Schulz and Eden, caregivers of a dependent older adult must fulfill multiple roles that exert an direct impact on their health and wellbeing ${ }^{4}$. Over time, the complexity of care increases, which is accompanied by an increase in responsibilities. This occurs with greater intensity in the context of family care. Therefore, caregivers subjected to long workweeks are at high risk of becoming ill.

Elder care in Brazil is mainly performed within the home environment, often by relatives and friends in a similar age range as the care recipient ${ }^{5,6}$. Many caregivers exercise functions for which they have no preparation, which can generate feelings of insecurity, fear and concern, intensifying the degree of burden and leading to frailty. Moreover, older caregivers face the challenges of their own aging, which when added to the demands of providing care, lead to greater vulnerability in comparison to older adults who do not provide care for anyone ${ }^{7}$. These conditions exert a considerable impact on the quality of life and life expectancy of caregivers.

Despite this greater vulnerability, the literature reports that the mortality rate of caregivers is considerably lower than that of non-caregivers or care recipients. One study found that the mortality of caregivers and non-caregivers in a six-year period was $7.5 \%$ and $9 \%$, respectively. ${ }^{8}$. Another study found that caregivers had a $16.5 \%$ lower mortality rate in a seven-year period compared to non-caregivers, refuting the hypothesis that poorer psychological conditions would affect caregivers more, as the effects of these conditions were only found in non-caregiving older adults ${ }^{9}$. Perceived Stress could be seen as an result of a sum of factors present in the context of care such a sleep difficulties, poor health perception, burden and having more people living with. These feeling in a long term could represent a risk for the health in older caregivers; however the construct has not been explored extensively in older caregivers ${ }^{10}$.
There seems to be a consensus that the mortality rates of caregivers are lower compared to their older non-caregiving peers ${ }^{9}$. However, the component factors of these differences are not yet clear, especially when looking for South American population. The investigation of differences between the two populations may contribute to improving healthcare for both older caregivers and care recipients considering family rearrangements and the increased burden to the family following the death of caregivers and non-caregivers in Brazil. In an attempt to fill this gap in knowledge, the aim of the present study was to analyze the mortality rates of Brazilian community-dwelling older adults who were providing support in activities of daily living (PC) and older adults who were receiving support in activities of daily living (RC) in a four-year period. A further aim was to analyze the effects of age, sex and schooling in both groups and the perceived stress in PC group. The hypothesis is that PC have a lower mortality rate than $\mathrm{RC}$, there are differences among subgroups divided according to age, sex and schooling, but PC who had been reported higher perceived stress could present with higher risk of mortality.

\section{METHODS}

\section{Design}

A longitudinal study with a four-year follow-up was conducted by the Health and Aging Group of the Federal University of São Carlos, Brazil.

\section{Participants}

We evaluated community-dwelling older adults registered with primary care centers in the city of São Carlos, state of São Paulo, Brazil. São Carlos is located in the Southeastern region of the country and has an estimated population of 221,950 residents, among whom $13 \%$ were aged 60 years or older according to the 2010 census ${ }^{11}$.

The baseline study was conducted in 2014 and was entitled "Variables Associated to Cognition in Older Caregivers". The study with primary analyses is described elsewhere ${ }^{12-14}$ but a participant selection process description is given here. Community-dwelling older adults (age $\geq 60$ years, as defined by the World Health Organization for developing countries) registered with 18 primary care centers $(n=1,188)$ in rural and urban areas of São Carlos were contacted in person and invited to participate in the survey. Individuals with hearing, visual or language limitations that would constitute barriers to the data collection process were excluded. During the home visits, trained researchers identified older persons who were providing care and support in activities of daily living (PC) and those who were receiving care and support in activities of daily living ( $R C)$. 
The response rate was 59.1\% (total: 702 individuals). The baseline sample comprised 351 older adults PC and 351 older adults RC. Providing help with Activity of Daily Living and receiving help with ADLs were the operational criteria to define both groups.

The follow-up data collection began in April 2018. Among the 351 PC in the baseline study, 22 participants had changed address (including those who went to nursing homes) and could not be contacted for the 2018 wave. Sixtyeight caregivers were lost to follow-up (not located at home after three attempts). Thus, the longitudinal study involved data on 261 PC (74.3\% of the baseline sample). Among these individuals, primary care services and family members confirmed 33 deaths. Among the 351 RC in the baseline study, 15 participants had changed address (including those who went to nursing homes) and could not be contacted for the 2018 wave. Fifty-seven participants were lost to followup (not located at home after three attempts). Thus, the longitudinal study involved data on 279 RC (79.5\% of the baseline sample). Among these individuals, primary care services and family members confirmed 87 deaths.

This study received approval from the Human Research Ethics Committee of the Federal University of São Carlos (certificate number: 1.123.813/2015). All participants signed a statement of informed consent at baseline and gave consent to participate in future studies. Trained professionals in the fields of gerontology and nursing conducted at-home interviews.

\section{Variables of interest and assessments}

- Demographic characteristics: sex (male, female), age (continuous variable and by range [60-69 y; 70-79 y; $\geq 80 \mathrm{y}]$ ), schooling (continuous variable and by category [illiterate; $1-4 y_{i} \geq 5 y$ ]).

- Basic activities of daily living: BADL index proposed by Katz et al. composed of six activities: feeding, sphincter control, transfer, hygiene, dressing and bathing. Individuals with one or more limitations regarding these activities were recorded as having "BADL limitation"15.

- Instrumental activities of daily living: IADL scale proposed by Lawton and Brody for the determination of the degree of dependence on activities such as performing housework, managing finances, using a telephone, administering medications, traveling, shopping and preparing meals. A perfect score is 21 (complete independence). Individuals with a score $\leq 20$ points were recorded as having "IADL limitation"16,17.

- Perceived stress was measured using the Perceived Stress Scale (PSS) developed to measure the level of stress experienced in the previous month. The PSS has 14 items with five response options ranging from "never" to "very often". The total ranges from 0 to 56 points, with higher scores denoting a higher level of stress. For the present study, the median of $\geq 17$ points was used as the cutoff point to define PC group with high and low levels of perceived stress $^{18,19}$.

- Mortality: for confirmed cases of death, the date of death was obtained from the primary care services and family members.

\section{Statistical analysis}

The Statistical Package for Social Sciences (SPSS software, version 21.0) was used for the data analysis. Descriptive statistics were performed to characterize the sample. Frequency (n), percentage (\%), mean and standard deviation $( \pm)$ values were calculated for the description of the participants at baseline (Table 1) and the prevalence of mortality assessed at follow-up (Table 2). The normal distribution of the data was assessed by the KolmogorovSmirnov test and parametric indicated tests were used during the analyses.

Two groups were considered: PC and RC. Mean age and schooling were compared using the t-test. Categorical variables (age group [reference: 60-69 y], sex [reference: men], schooling [reference: $\geq 5$ y], BADL limitation and IADL limitation [reference: independence]) were compared using Pearson's chi-squared $\left(X^{2}\right)$ test. We tested the association between mortality and age ( $\geq 80 y_{;} 70-79 y_{;}$60-69y) sex (female; male) and schooling (illiterate; $1-4 y_{i} \geq 5$ y) in each group ( $\mathrm{PC}$ and $\mathrm{RC}$ ). Specifically, we tested the association between mortality rate and perceived stress (PSS $\geq 17$, reference: 0-16). Single Cox regression models were run to analyze the effects (hazard ratio [HR] and respective confidence intervals [95\% Cl]) of factors associated with the event of death among PC and RC (unadjusted column; Table 2). ADL and IADL limitation (reference: independence) and age (continuous) were the controlling variables (adjusted column, Table 2).

Figures 1 and 2 were constructed using Prism GraphPad 7.04 to illustrate the cumulative survival curve in $P C$ and RC (Figure 1) and in each group considering sex (Figure 2). Additionally, the Figure 3 illustrates the cumulative survival curve in PC considering level of perceived stress. The component "time of event" was described in the overall mean and compared using the t-test. We adopted the 5\% significance level ( $p \geq 0.05)$.

\section{RESULTS}

The characteristics of the 261 older adults providing support in $\mathrm{ADL}(\mathrm{PC})$ and 279 older adults receiving support in ADL (RC) included in the sample are displayed in Table 1. 
Table 1. Baseline characteristics of 540 PC and RC from "Variables Associated to Cognition in Older Caregivers" study - São Carlos, Brazil, 2014

\begin{tabular}{|c|c|c|c|}
\hline Characteristics & $\begin{array}{c}\text { PC } \\
n=261 \\
n(\%) \text { or mean } \pm \text { SD }\end{array}$ & $\begin{array}{c}\mathrm{RC} \\
\mathrm{n}=\mathbf{2 7 9} \\
\mathrm{n}(\%) \text { or mean } \pm \mathrm{SD}\end{array}$ & $\begin{array}{l}\text { Statistics; } \\
\text { p-value }\end{array}$ \\
\hline Age, y & $69.71 \pm 6.93$ & $74.27 \pm 8.60$ & $\mathrm{~T}:-6.7 ;<.001$ \\
\hline $60-69$ & $144(55.2)$ & $98(35.1)$ & ref \\
\hline $70-79$ & 89 (34.1) & $112(40.1)$ & $X^{2}:$ 10.2; .001 \\
\hline $80+$ & $28(10.7)$ & $69(24.7)$ & $X^{2}: 26.0 ;<.001$ \\
\hline Men & $60(23.0)$ & $190(68.1)$ & $X^{2}: 110.3 ;<.001$ \\
\hline Women & $201(77.0)$ & 89 (31.9) & \\
\hline Schooling, y & $3.59 \pm 3.31$ & $3.47 \pm 3.80$ & T: 0.393; .696 \\
\hline Illiterate & $54(20.7)$ & 79 (38.3) & $X^{2}: 1.8 ; .181$ \\
\hline $1-4$ & $157(60.2)$ & $148(53.0)$ & $X^{2}: 0 ; 1$ \\
\hline $5+$ & 50 (19.2) & 48 (17.2) & ref \\
\hline Missing & - & $4(1.4)$ & \\
\hline BADL limitation & $34(13.0)$ & 95 (34.1) & $X^{2}: 32.7 ;<.001$ \\
\hline IADL limitation & $153(58.6)$ & $279(100)$ & $X^{2}: 144.1 ;<.001$ \\
\hline PSS (0-56) & $19.16(9.8)$ & - & - \\
\hline Lower (<17) & $113(43.8)$ & - & - \\
\hline Higher $(\geq 17)$ & 145 (56.3) & - & - \\
\hline
\end{tabular}

BADL: activities of daily living; IADL: instrumental activities of daily living; PSS: Perceived Stress Scale; SD: standard deviation.

Differences in the variables were found between the $\mathrm{PC}$ and $\mathrm{RC}$, with the exception of schooling. On average, the RC were four years older than the PC. The "80 years or older" age group was also more prevalent in the group of RC. Moreover, the group of RC was composed predominantly of men and had more individuals with limitations regarding both BADL and IADL.

The mortality rate between baseline and follow-up was $12.6 \%$ (33 individuals) among the PC and 31.2\% (87 individuals) among the RC. Among the confirmed deaths in the group of PC, 31 individuals (93.9\%) had no limitations regarding $\mathrm{BADL}$, but 23 (69.7\%) had some limitation regarding IADL. Nineteen PC who died (57.6\%) were women and 20 (60.6\%) were 70 years of age or older. Mean age at baseline of the PC who died during the follow-up period was $73.8 \pm 9$ years. Seven of the PC who died (21.2\%) were illiterate and 20 (60.6\%) had between one and four years of schooling. Mean schooling in the group was $4.21 \pm 4.41$ years. It was possible to determine when death occurred in 24 of the 33 cases. On average, death occurred 2.1 years after the baseline evaluation, occurring within the first two years after baseline in 15 cases (62.5\%).

Among the deaths in the group of $\mathrm{RC}$, all individuals were dependent with regard to IADL and 51 (58.6\%) were independent regarding BADL. Thirty-eight RC (56.3\%) were men and 71 (81.6\%) were 70 years of age or older. Mean age at baseline of the PC who died during the follow-up period was $78.7 \pm 9.15$ years. Thirty-two (36.8\%) were illiterate and 43 (49.4\%) had between one and four years of schooling. Mean schooling in the group was 3.34 years. It was possible to determine when death occurred in 57 of the 87 cases.
On average, death occurred 2.1 years after the baseline evaluation, occurring within the first two years after baseline in 28 cases $(49.1 \%)$.

From the 33 deaths of PC, 23 PC (corresponding to $69 \%$ of total of deaths) had a high level of perceived stress. The mortality rate in the low perceived stress group was 8.8\% while in the high-perceived stress was $15.9 \%$ during the follow-up. Forty-three percent of death in PC with low perceived stress happened in the first two years of the followup while $62.5 \%$ of the death of PC with high-perceived stress happened in the same period.

In general, RC died at a twofold greater proportion compared to the PC (Figure 1). The mean time to death after baseline was the same in both groups. Table 2 displays the results of the regression analyses for deaths in the groups of PC and RC. No effects were found for age, sex or schooling, and for perceived stress in the PC groups. In the group of RC, the female sex was marginally associated with death when the model was adjusted for BADL and IADL limitations and age.

Eighty-nine women were in this group, 39 of whom $(42.7 \%)$ died in the four-year follow-up period. Among the 190 men in the group of RC, 49 (25.8\%) died in the four-year follow-up period, which is a significantly smaller proportion in comparison to the women. However, time to death was significantly longer among the women ( 2.4 versus $1.8 ; p=$ 0.035). Thus, male RC died in a shorter period of time after baseline, as shown by the survival curve in Figure 2. In similar finding, PC with high-perceived stress deceased in higher proportion and faster compared with PC with lower perceived stress (Figure 3). 
Table 2. Association between mortality in four-year period among PC and RC in relation to age, sex and schooling in unadjusted analysis and analysis adjusted for measures of functional independence - São Carlos, 2014-2018

\begin{tabular}{|c|c|c|c|c|c|c|c|c|}
\hline & \multicolumn{2}{|c|}{ n (\%) Died } & \multicolumn{3}{|c|}{ Unadjusted } & \multicolumn{3}{|c|}{ BADL/IADL-Adjusted } \\
\hline & $n / N$ & $\%$ & HR & $95 \% \mathrm{Cl}$ & $\mathbf{p}$ & HR & $95 \% \mathrm{Cl}$ & p \\
\hline \multicolumn{9}{|l|}{ Age factor $(70-79 \mathrm{y})$} \\
\hline Care/support Recipients & $32 / 87$ & 36.8 & 1.5 & $0.7-3.1$ & .289 & 1.5 & $0.7-3.1$ & .287 \\
\hline Care/Support Providers & $12 / 33$ & 36.4 & 1.7 & $0.6-4.4$ & .275 & 1.5 & $0.5-4.2$ & .383 \\
\hline \multicolumn{9}{|l|}{ Age factor (+80 y) } \\
\hline Care/support Recipients & $39 / 87$ & 44.8 & 1.6 & $0.8-3.3$ & .137 & 1.7 & $0.8-3.5$ & .121 \\
\hline \multirow[t]{3}{*}{ Care/Support Providers } & $8 / 33$ & 24.2 & 1.2 & $0.3-3.8$ & .746 & 1.3 & $0.3-4.4$ & .688 \\
\hline & \multicolumn{2}{|c|}{ n (\%) Died } & \multicolumn{3}{|c|}{ Unadjusted } & \multicolumn{3}{|c|}{ BADL/IADL/age-Adjusted } \\
\hline & $\mathrm{n} / \mathrm{N}$ & $\%$ & HR & $95 \% \mathrm{Cl}$ & $\mathbf{p}$ & HR & $95 \% \mathrm{Cl}$ & $\mathbf{p}$ \\
\hline \multicolumn{9}{|l|}{ Sex factor (women) } \\
\hline Care/support Recipients & $49 / 87$ & 56.3 & 1.7 & $0.9-2.9$ & .060 & 1.7 & $0.9-3.0$ & .069 \\
\hline Care/Support Providers & $14 / 33$ & 42.4 & 1.2 & $0.5-2.7$ & .654 & 0.7 & $0.2-1.8$ & .491 \\
\hline \multicolumn{9}{|l|}{ Schooling factor (Illiterate) } \\
\hline Care/support Recipients & $32 / 86$ & 36.8 & 1.2 & $0.5-2.7$ & .538 & 1.4 & $0.5-3.6$ & .496 \\
\hline Care/Support Providers & $7 / 33$ & 21.2 & 1.3 & $0.3-4.6$ & .696 & 0.7 & $0.1-3.5$ & .669 \\
\hline \multicolumn{9}{|l|}{ Schooling factor (1-4 y) } \\
\hline Care/support Recipients & $43 / 86$ & 49.4 & 1.0 & $0.5-2.1$ & .964 & 0.7 & $0.3-1.6$ & .453 \\
\hline Care/Support Providers & 20/33 & 60.6 & 1.0 & $0.3-3.2$ & .946 & 0.9 & $0.3-3.0$ & .922 \\
\hline \multicolumn{9}{|l|}{ Perceived Stress ( $\geq 17)$} \\
\hline Care/Support Providers & $23 / 33$ & 69.7 & 0.8 & $0.3-1.9$ & .813 & 0.7 & $0.2-1.8$ & .485 \\
\hline
\end{tabular}

BADL: basic activities of daily living; IADL: instrumental activities of daily living; HR: hazard ratio.

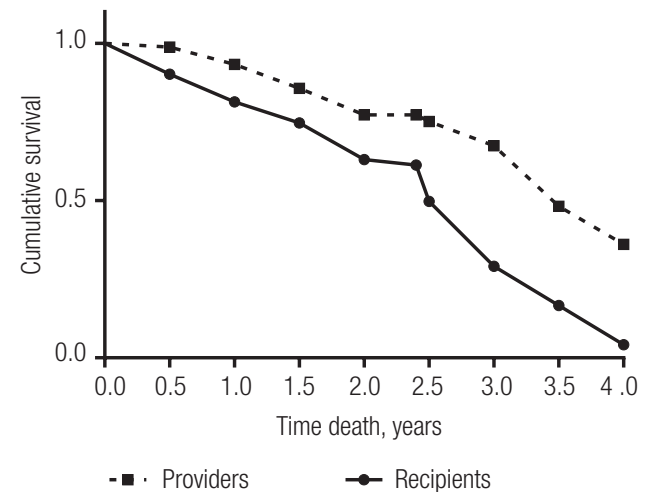

Figure 1. Cumulative survival for PC and RC (São Carlos, 2014-2018)
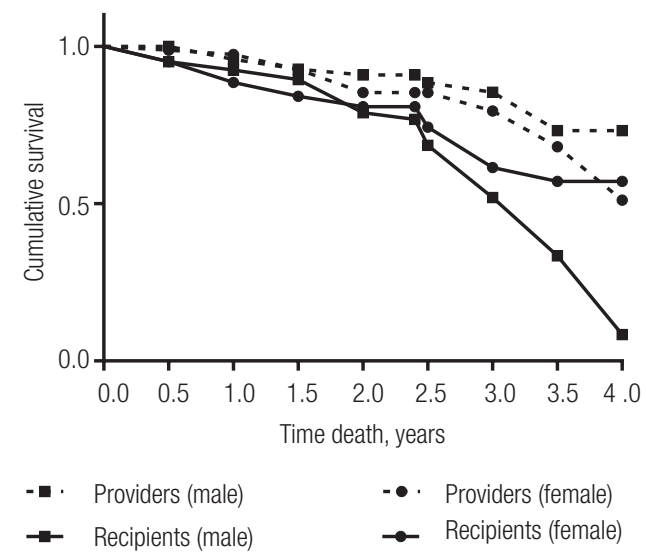

Figure 2. Cumulative survival for $P C$ and $R C$ stratified by sex (São Carlos, 2014-2018)

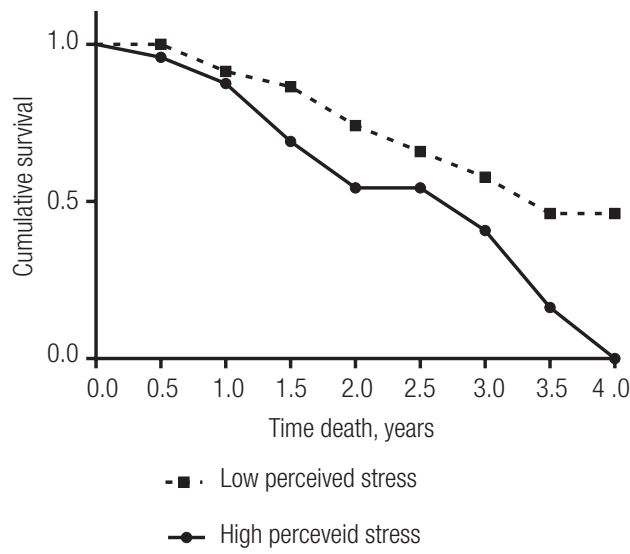

Figure 3. Cumulative survival for PC stratified PPS score (low perceived stress/high perceived stress) (São Carlos, 2014-2018)

\section{DISCUSSION}

Among the 540 older PC and RC in the 2014 sample, 120 (22.2\%) died during the four-year follow-up period. Among these individuals, 33 were care providers $(P C)$ and 87 were care recipients $(\mathrm{RC})$, demonstrating a higher mortality rate among the RC. At baseline, the RC were predominantly men, were older and had more limitations regarding activities of daily living compared to the PC. In the group of PC, none of the variables evaluated was associated with the occurrence 
of death. In the group of RC, however, the female sex had a hardly noticeable association with the occurrence of death. PC with high-perceived stress died at a twofold greater proportion compared to the PC with low perceived stress.

The literature reports that caregivers of older adults are generally in the same age group as the care recipient, although the care recipients are slightly older ${ }^{12,20}$. Most often, the caregiver is the wife, daughter or daughter-in-law of the care recipient and is at risk in terms of health due to the long hours dedicated to care as well as the occurrence of stress and excessive burden ${ }^{6,21}$. Nonetheless, providing care for an older adult is a form of social engagement that may prevent feelings of loneliness. Indeed, a lack of social engagement and feelings of isolation are considered risk factors for depression and disability in old age $\mathrm{e}^{22,23}$.

Providing care to a dependent person can endorse a sense of belonging, as well as promoting the feeling of being an important actor for the functioning of that society. Likewise, having an active posture in care can provide closer contact with other actors related to care, such as other family members and friends, health and social professionals, charity and shops, care associations and research and development institutions.

In the cross-sectional analysis at baseline, the majority of care recipients were more dependent than the caregivers. This finding is likely due to the recruitment method employed in the study, as the sample was composed of older adults cohabitating with other older adults in a situation in which one provided assistance to the other. The literature also shows that a low degree of functioning often occurs among older adults who live alone. Living alone and not receiving assistance from others has been associated with poor functioning among non-caregivers, as demonstrated in surveys conducted with older adults in Brazil24,25.

The mortality rate was lower in the group of PC compared to RC. The literature emphasizes the need for more specialized care for caregivers. Since the beginning of the century, mortality has been studied as an adverse outcome in caregivers, especially those with excessive burden, and the effect of stress during the course of one's life is an important aspect of the risk of death in old age. Literature figures the risk of death is lower among caregivers compared to non-caregivers but increases in the occurrence of reports of psychological stress. A previous study reports that feelings of stress during the course of one's life increases the risk of death, with an odds ratio of 1.42 for moderate stress and 1.37 for high stress, independently of the relation to providing care to a dependent older person ${ }^{26}$. In the study, data from 1,143 older men showed that the participants with any feelings of stress also had a $50 \%$ greater chance of dying after controlling for marital status, schooling, selfrated health, the use of alcoholic beverages and smoking.
Being married and a good self-assessment of health had a protective effect, whereas being a smoker and not using alcohol were associated with the risk of mortality ${ }^{26}$.

A follow-up study with 375 caregivers of older family members or friends compared to 694 non-caregivers found that the adjusted ratio for the risk of death was 0.74 , but caregivers with high levels of stress had an adjusted ratio of 1.81 for mortality in the first three years compared to those with low stress, equaling the risk of mortality found for older non-caregivers. Among caregivers who were spouses with a high level of stress, the ratio of mortality was 1.70 in the first three years, which was the same as the ratio for noncaregivers with a conjugal life ${ }^{27}$. Similar results are reported in a five-year study involving 3710 older adults who provided some type of care to a dependent family member, in which more burdened caregivers had a higher risk of mortality compared to those with some care-related burden $(H R=$ 1.55) or no burden $(H R=1.83)^{21}$.

A study involving 3,075 participants also found a greater risk for death and functional dependence among noncaregivers compared to caregivers. However, caregivers who provided care 24 or more hours per week tended to have higher rates of functional decline after eight years. In the same study, self-declared white caregivers had a 1.5fold higher mortality rate compared to self-declared black caregivers $^{28}$. Another investigation with 3,503 caregivers matched with 3,503 non-caregivers found different results for subgroups of caregivers. As in other studies, the mortality rate was $18 \%$ lower among the caregivers compared to the non-caregivers, but the analyses did not reveal an increase in rates in subgroups based on ethnicity, sex or time per week dedicated to care. The relationship to the care recipient had an effect; caregivers who were sons/daughters of the care recipient had lower mortality rates 8 .

No longer providing care for a loved one or becoming a caregiver during a follow-up period can alter the odds ratios for death. A 10-year investigation with 1068 older women, $35 \%$ of whom were caregivers, found a $38.8 \%$ mortality rate for caregivers and $48.7 \%$ for non-caregivers. Among the women who were caregivers at baseline, the HR for death was 0.77 (95\% Cl: 0.62-0.95) and the ratio diminished in the first three years after no longer being in the role of caregiver, but increased to similar levels as those found for non-caregivers in a five-year period ${ }^{29}$. There seems to be a consensus in the literature that caregivers have lower mortality rates compared to non-caregiving peers ${ }^{9}$.

Age has been found to be the main factor associated with mortality and older males appear to be more affected by the outcome $e^{30,31}$. These two characteristics were more prevalent in the group of RC, which may explain the earlier deaths in this group. However, the Cox regression analysis in which time was incorporated showed that older female RC 
died at a larger proportion that male RC. Few studies were found in the literature for the discussion of this outcome. Studies discussing the mortality of women show that they are more susceptible to the outcome due to the occurrence of diseases, such as cardiovascular disease and cancer, as well as functional limitations and lifestyle factors, such as physical inactivity ${ }^{32-35}$.

The present study has limitations that should be considered. The RC have had a higher prevalence of the outcome compared to the PC, which also could be influenced by the advanced age of this group, together with the high prevalence of functional limitation. The investigation included all causes of mortality among the participants. Specific causes and previous conditions potentially related to death, such as hospitalization, loss of functioning and institutionalization, were not recorded. Such information would furnish greater detail regarding the profile of mortality among the $P C$ and $R C$ in the present sample. The small number of participants limited the data analysis in terms of considering other aspects of the care context as adjustment variables. Additionally, future address could include comorbidities covariates. However, the study was specific in recruiting PC and RC and had a similar number of participants as those in previous studies that also investigated the mortality of PC. The fact that the RC were older adults who received some type of care may limit the interpretation of the results. However, the control variables in the regression analysis (basic and instrumental activities of daily living) minimized the effects of this limitation.

The present findings have clinical implications considering the offer of care by older adults to other older adults living in communities in Brazil. Older adults providing daily support may be somewhat younger and have greater functional capacity compared to the support recipients, but special attention should be given to those who feel burdened by the care. This situation can compromise mental, cognitive and physical health, making the provider as vulnerable as the recipient. Older adults receiving daily support may be more functionally limited and many, such as female $\mathrm{RC}$ and more stressed $\mathrm{PC}$, may be at greater risk of adverse health outcomes, which can exert a negative impact on their wellbeing and the wellbeing of their families.

These findings might be important for the care planning, especially in a (meso) management perspective, and highlight the importance for stress-reduced interventions focused to people with advanced age and low formal education. The healthcare system that reunites actions toward the wellbeing of the older people may prioritizes the risk assessment for adverse outcomes and develop actions to protect the health of the most vulnerable. Actions in the primary health and social care such as emotional and psychological support, physical activities and rehabilitation of previous conditions, social and financial support through social services and leisure are examples of holistic strategies that effectively promote the wellbeing and quality of life and reduces risks for those providing and receiving care.

\section{CONCLUSIONS}

The mortality rate of older adults who were receiving support in the four-year follow-up period was twice the rate of older adults who were providing support. At baseline, the PC were predominantly women, were younger and had better functional capacity than the RC had. Male RC had a lower mortality rate, but the time of the occurrence of death in the four-year period was shorter compared to female RC. PC with high stress also presented with more proportion of deaths. The outcomes studied underscore the importance of designing strategies for the management and follow-up of families with older adults considering demographic and care-related characteristics.

\section{INDIVIDUAL CONTRIBUTION}

Allan Gustavo Bregola, Ana Carolina Ottaviani, Bruna Designed the study, collected and supervised the data collection and wrote the paper.

Allan Gustavo Bregola - Was responsible for the statistical design of the study and for carrying out the statistical analysis.

\section{CONFLICT OF INTEREST}

All authors of this study have no conflicts of interest to declare.

\section{ACKNOWLEDGMENTS}

The authors are grateful to all the participants. This study was funded by the Fundação de Amparo à Pesquisa do Estado de São Paulo (Fapesp [State of São Paulo Research Foundation] Grant numbers 2013/26798-9; 2017/04129-9; 2018/00265-8) and Conselho Nacional de Desenvolvimento Científico e Tecnológico (CNPq [National Council for Scientific and Technological Development] Grant numbers 304067/2015-6; 306571/2018-8).

\section{REFERENCES}

1. Pinquart M, Sorensen S. Associations of stressors and uplifts of caregiving with caregiver burden and depressive mood: a meta-analysis. J Gerontol B Psychol Sci Soc Sci. 2003:58(2):P112-28. 
2. Pinquart $M$, Sorensen $S$. Differences between caregivers and noncaregivers in psychological health and physical health: a meta-analysis. Psychol Aging. 2003;18(2):250-67.

3. Pinquart $M$, Sorensen $S$. Gender differences in caregiver stressors, social resources, and health: an updated meta-analysis. J Gerontol B Psychol Sci Soc Sci. 2006;61(1):33-45.

4. Schulz R, Eden J. Family Caregiving Roles and Impacts. In: Schulz R, Eden J, editors. Families Caring for an Aging America [Internet]. Washington DC: National Academies Press (US); 2016. Available from: https://www.ncbi.nlm.nih.gov/books/NBK396398/. Accessed in: Apr 13, 2021.

5. Santos-Orlandi AA, Brito TRP, Ottaviani AC, Rossetti ES, Zazzetta MS, Gratão ACM, et al. Profile of older adults caring for other older adults in contexts of high social vulnerability. Esc Anna Nery. 2017;21(1).

6. Pavarini SCl, Neri AL, Brígola AG, Ottaviani AC, Souza ÉN, Rossetti ES, et al. Elderly caregivers living in urban, rural and high social vulnerability contexts. Rev Esc Enferm USP. 2017.

7. Brigola A, Barbieri M, Luchesi BM, Grazziano ES, Machado RC, Dupas G, et al. Association between depressive syndrome and visual complaints among elderly caregivers. J Bras Psiquiatr. 2018;67(4):223-30.

8. Roth DL, Haley WE, Hovater M, Perkins M, Wadley VG, Judd S. Family caregiving and allcause mortality: Findings from a population-based propensity-matched analysis. Am J Epidemiol. 2013;178(10):1571-8.

9. Roth DL, Brown SL, Rhodes JD, Haley WE. Reduced mortality rates among caregivers: Does family caregiving provide a stress-buffering effect? Psychol Aging. 2018;33(4):619-29.

10. Luchesi BM, Souza ÉN, Gratão ACM, Gomes GAO, Inouye K, Alexandre TS, et al. The evaluation of perceived stress and associated factors in elderly caregivers. Arch Gerontol Geriatr. 2016;67:7-13.

11. Instituto Brasileiro de Geografia e Estatística. Censo demográico 2010 [Internet]. 2010. Available from: http://www.ibge.gov.br/home/estatistica/populacao/censo2010/default. shtm. Accessed in: Apr 13, 2021.

12. Brigola AG, Luchesi BM, Alexandre TS, Inouye K, Mioshi E, Pavarini SCI. High burden and frailty: association with poor cognitive performance in older caregivers living in rural areas. Trends Psychiatry Psychother. 2017;39(4):257-63.

13. Luchesi BM, Alexandre TDS, De Oliveira NA, Brigola AG, Kusumota L, Pavarini SCl, et al. Factors associated with attitudes toward the elderly in a sample of elderly caregivers. Int Psychogeriatrics. 2016;28(12).

14. Pavarini SCl, Brigola AG, Ottaviani AC, Luchesi BM, Souza ÉN, Rossetti ES, et al. Factors associated with cognitive performance in elderly caregivers. Arq Neuropsiquiatr. 2018;76(10):685-91.

15. Katz S, Ford AB, Moskowitz RW, Jackson BA, Jaffe MW. Studies of illness in the aged. The index of ADL: a standardized measure of biological and psychosocial function. JAMA. 1963;185:914-9.

16. Lawton MP, Brody EM. Assessment of older people: self-maintaining and instrumental activities of daily living. Gerontologist. 1969;9(3):179-86.

17. Santos RL, Virtuoso Júnior JS. Reliability of the Brazilian version of the Scale of Instrumental Activities of Daily Living. Rev Bras Promoção Saúde. 2008;21(4):290-6.

18. Cohen S, Kamarck T, Mermelstein R. A global measure of perceived stress. J Health Soc Behav. 1983;24(4):385-96.
19. Luft CDB, Sanches SO, Mazo GZ, Andrade A. Versão brasileira da Escala de Estresse Percebido: tradução e validação para idosos. Rev Saude Publica. 2007;41(4):606-15.

20. Bierhals CCBK, Santos NO, Fengler FL, Raubustt KD, Forbes DA, Paskulin LMG. Needs of family caregivers in home care for older adults. Rev Lat Am Enfermagem. 2017;25:e2870.

21. Perkins M, Howard VJ, Wadley VG, Crowe M, Safford MM, Haley WE, et al. Caregiving strain and all-cause mortality: Evidence from the REGARDS study. I Gerontol B Psychol Sci Soc Sci. 2013;68(4):504-12.

22. Bandari R, Khankeh HR, Shahboulaghi FM, Ebadi A, Keshtkar AA, Montazeri A. Defining Ioneliness in older adults: protocol for a systematic review. Syst Rev. 2019;8(1):26.

23. Landeiro F, Barrows P, Nuttall Musson E, Gray AM, Leal J. Reducing social isolation and Ioneliness in older people: a systematic review protocol. BMJ Open. 2017;7(5):e013778.

24. Negrini ELD, Nascimento CF, Silva A, Antunes JLF. Elderly persons who live alone in Brazil and their lifestyle. Rev Bras Geriatr Gerontol. 2018;21(5):523-31.

25. Elias HC, Marzola TS, Molina NPFM, Assunção LM, Rodrigues LR, Tavares DMS. Relation between family functionality and the household arrangements of the elderly. Rev Bras Geriatr Gerontol. 2018;21(5):562-9.

26. Aldwin CM, Molitor NT, Avron S 3rd, Levenson MR, Molitor J, Igarashi H. Do Stress Trajectories Predict Mortality in Older Men? Longitudinal Findings from the VA Normative Aging Study. J Aging Res. 2011;2011:896109.

27. Fredman L, Cauley JA, Hochberg M, Ensrud KE, Doros G. Mortality associated with caregiving, general stress, and caregiving-related stress in elderly women: Results of caregiver-study of osteoporotic fractures. J Am Geriatr Soc. 2010;58(5):937-43.

28. Fredman L, Cauley JA, Satterfield S, Simonsick E, Spencer SM, Ayonayon HN, et al. Caregiving, mortality, and mobility decline: the Health, Aging, and Body Composition (Health ABC) Study. Arch Intern Med. 2008;168(19):2154-62.

29. Fredman L, Lyons JG, Cauley JA, Hochberg M, Applebaum KM. The relationship between caregiving and mortality after accounting for time-varying caregiver status and addressing the healthy caregiver hypothesis. J Gerontol A Biol Sci Med Sci. 2015;70(9):1163-8.

30. Kara 0, Canbaz B, Kizilarslanoglu MC, Arik G, Sumer F, Aycicek GS, et al. Which parameters affect long-term mortality in older adults: is comprehensive geriatric assessment a predictor of mortality? Aging Clin Exp Res. 2017;29(3):509-15.

31. Llamas-Velasco S, Villarejo-Galende A, Contador I, Lora Pablos D, Hernández-Gallego J, Bermejo-Pareja F. Physical activity and long-term mortality risk in older adults: A prospective population based study (NEDICES). Prev Med Reports. 2016;4:546-50.

32. Brown WJ, McLaughlin D, Leung J, McCaul KA, Flicker L, Almeida OP, et al. Physical activity and all-cause mortality in older women and men. Br J Sports Med. 2012;46(9):664-8.

33. Seguin R, Buchner DM, Liu J, Allison M, Manini T, Wang CY, et al. Sedentary behavior and mortality in older women: the Women's Health Initiative. Am J Prev Med. 2014;46(2):122-35.

34. Stevens $G A$, Mathers $C D$, Beard JR. Global mortality trends and patterns in older women. Bull World Health Organ. 2013;91(9):630-9.

35. Izano M, Satariano WA, Hiatt RA, Braithwaite D. The impact of functional limitations on long-term outcomes among African-American and white women with breast cancer: a cohort study. BMJ Open. 2013;3(10):e003232. 